\title{
ARQUIVOS: TERRITÓRIOS INDÍGENAS
}

\author{
ANA PAULA SILVA ${ }^{1}$
}

\begin{abstract}
RESUMO
0 presente artigo ${ }^{2}$ propõe uma reflexão sobre a importância dos acervos brasileiros para os estudos da população indígena em espaços urbanos, particularmente na cidade do Rio de Janeiro oitocentista, compartilhando assim os resultados de minha recente pesquisa. Compreendendo os arquivos como territórios indígenas, esta abordagem está inserida num diálogo interdisciplinar, sobretudo entre a história e a antropologia, que vem contribuindo para a construção do conhecimento da História Indígena. Para isso, a análise abarcará informações contidas em distintos documentos do século XIX.
\end{abstract}

\section{PALAVRAS-ChAVE}

Indígenas na cidade; Rio de Janeiro; Arquivos; Territórios Indígenas

\section{ARCHIVE: INDIGENOUS TERRITORIES}

\begin{abstract}
This article proposes a reflection on the importance of the Brazilian collections for the study of the indigenous population in urban spaces, particularly in the $19^{\text {th }}$ century Rio de Janeiro city, thus sharing the results of my recent research. Comprising archives as indigenous territories, this approach is embedded in an interdisciplinary dialogue, especially between history and anthropology, which has been contributing to the construction of knowledge of Indigenous History. For the, the analysis will include information contained in different documents of the $19^{\text {th }}$ century.
\end{abstract}

\section{KEYWORDS}

Indigenous people in the city; Rio de Janeiro; Archives; Indigenous Territories

\section{ARCHIVES: TERRITOIRES AUTOCHTONES}

\section{RÉSUMÉ}

Cet article propose une réflexion sur l'importance des collections brésiliennes pour l'étude de la population autochtone dans les espaces urbains, particulièrement dans la ville de Rio de Janeiro au 19e siècle, en partageant les résultats de ma récente recherche. Comprennent les archives comme des territoires indigènes, cette approche s'insère dans un dialogue interdisciplinaire, surtout entre l'histoire et l'anthropologie, contribuant à la construction du connaissance d'Historie Indigène. Pour cela, l'analyse comprend les informations contenues dans différents documents du XIXe siècle.

\footnotetext{
${ }^{1}$ Doutora pelo Programa de Pós-Graduação em Memória Social, da Universidade Federal do Estado do Rio de Janeiro (PPGMS-UNIRIO, 2016). Atua como formadora na Ação Saberes Indígenas na Escola (ASIE), Núcleo UERJ/UFMG.

2 O presente artigo inspirado na tese de doutorado defendida, em 2016, no Programa de PósGraduação em Memória Social, da UNIRIO, sob a orientação do Prof. Dr. José Ribamar Bessa Freire.
} 


\section{MOTS-CLÉS}

Autochtones dans la ville; Rio de Janeiro; Archives; Territoires autochtones.

\section{ARCHIVOS: TERRITORIOSINDÍGENAS}

\section{RESUMEN}

El presente artículo propone una reflexión sobre la importancia de los acervos brasileños para los estudios de la población indígena en espacios urbanos, particularmente en la ciudad de Río de Janeiro ochocentista, compartiendo así los resultados de mi reciente investigación. Comprendiendo a los archivos como territorios indígenas, este enfoque insertarse en un diálogo interdisciplinario, sobre todo entre la historia y la antropología, que viene contribuyendo a la construcción del conocimiento de la Historia Indígena. Para ello, se analizan informaciones contenidas en distintos documentos del siglo XIX.

\section{PALABRAS CLAVE}

Indígenas en la ciudad; Rio de Janeiro; Archivos; Territorios Indígenas 


\section{INTRODUÇÃO}

"Não tenho um caminho novo. O que eu tenho de novo é um jeito de caminhar". (Thiago de Melo)

Arquivos, coleções etnográficas e pessoais, assim como os documentos históricos (textuais, imagéticos, sonoros, além dos artefatos), passaram a ter maior visibilidade para historiadores e antropólogos, interessados na presença e participação indígena nos processos de formação sociocultural da sociedade brasileira no período colonial e pósindependência. O interesse desses pesquisadores, nos últimos anos, se deve (entre outros fatores) à iniciativa de mapear, digitalizar acervos arquivísticos nacionais e internacionais relacionados à história do Brasil e à produção de instrumentos de pesquisas como catálogos, guias de fontes, inventários (alguns específicos sobre a(s) temática(s) dos povos indígenas no Brasil). Por outro lado, cresce o interesse dos antropólogos nas instituições arquivísticas, arquivos etnográficos e de pesquisas pessoais, além dos acervos imagéticos e sonoros utilizados como importantes recursos metodológicos do trabalho campo, fomentando análises diversas sobre temas e temporalidades distintas. Os próprios índios vêm se apropriando do audiovisual como ferramenta política de garantias de direitos e denúncias de violações sofridas, formas de registro cultural e linguístico, novas tecnologias da memória, entre outras apropriações.

Nesse movimento em direção aos arquivos e coleções, alguns antropólogos têm desenvolvido pesquisas sobre e nos arquivos, campo da antropologia que está sendo denominado de antropologia do/no arquivo, devido à dupla perspectiva de análise (CASTRO e CUNHA, 2005). Estabelecendo um diálogo entre a história e a antropologia, compreendendo os arquivos como territórios indígenas, este artigo discute a relevância dos acervos de instituições arquivísticas para os estudos da presença indígena em contexto urbano, especialmente na cidade do Rio de Janeiro no século XIX. Рara descrever e interpretar as informações contidas nos acervos arquivísticos, é necessário uma atividade investigativa minuciosa tal como propõe Ginzburg (1991). Nesse sentido, reuni pistas, vestígios e sinais presentes na documentação de época e montando quebra-cabeças, identifiquei um fluxo de índios se deslocando, ao longo de todo o Oitocentos, à capital do reino, posterior Império.

\section{HISTORIADORES E ÍNDIOS}

Nas últimas décadas, a temática dos povos indígenas vem despertando o interesse de diversos historiadores no Brasil. O tema índios era primazia de campos como a antropologia e a linguística, todavia com o advento da chamada Nova História Indígena ou somente História Indígena (MONTEIRO, 2001) - que visa compreendê-los como 
atores/protagonistas do processo histórico - inúmeras pesquisas de caráter interdisciplinares estão sendo desenvolvidas, em cursos e programas de pós-graduação de história no país, sobre a presença e participação indígena nos processos de formação de sociedades coloniais e pós-coloniais. Movimento que tem levado um número significativo de historiadores a valorizar e pesquisar documentos de arquivos nacionais e estrangeiros, desconstruindo abordagens clássicas acerca dessas populações.

Рara John Monteiro (2007), essa mudança de perspectiva resultou, entre outros fatores, das pressões de líderes e das primeiras organizações representativas dos povos indígenas nos anos 70 sobre as políticas indigenistas oficiais, contestando a tutela exercida pelo Estado em função da suposta "incapacidade" e "primitivismo" dessas sociedades. A Constituição brasileira de 1988, como resultado das lutas e reivindicações indígenas (não apenas), reconheceu os índios como sujeitos de direito e reverteu (ainda que parcialmente) o caráter "civilizador" e assimilacionista das políticas indigenistas "Ela abandona a tradição assimilacionista e encampa a ideia - a realidade dos fatos - de que os índios são sujeitos presentes e capazes de permanecer no futuro" (SANTILI, 2000, p. 29). A reconfiguração da noção dos direitos indígenas como direitos históricos - sobretudo territoriais e de reafirmação étnica - estimulam importantes estudos que buscam nos documentos coloniais (e nas instituições arquivísticas) os fundamentos históricos, antropológicos e jurídicos das demandas atuais dos povos indígenas e de seus defensores.

Nessa discussão, penso ser fundamental mencionar o lançamento do livro "História dos Índios no Brasil" (1992), organizado pela antropóloga Manuela Carneiro da Cunha, marco importante para os estudos dos povos indígenas no Brasil. A obra reúne análises de diferentes especialistas em áreas como história, antropologia, linguística, arqueologia, encontrando-se ali a urgência de se escrever outra narrativa histórica, na qual os índios sejam agentes de suas próprias histórias, conforme salientou Carneiro da Cunha (1992, p 18) "A percepção de uma política e de uma consciência histórica em que os índios são sujeitos e não apenas vítimas, só é nova eventualmente para nós". Contribuíram ainda para dar visibilidade e chamar a atenção dos pesquisadores, diversos projetos de mapeamento de documentação produzida pore sobre indígenas em contexto de suas interações socioculturais e políticas no período colonial e pós-colonial. Instrumentos de pesquisas esses fundamentais na difícil tarefa de localização desses tipos de documentos nas instituições arquivísticas.

Segundo Juciene Ricarte (2011), a elaboração e publicação de importantes instrumentos de pesquisa - como guias, inventários e catálogos - são o modo mais rápido e eficiente de acesso aos documentos históricos, por apresentar um panorama mais preciso dos acervos arquivísticos. Eles dão visibilidade às chamadas fontes, criando assim fronteiras, mapas dentro dos arquivos, que nos permite localizar e acessar os manuscritos com maior agilidade. Dentro dessa produção sobre a história indígena e do indigenismo brasileiro, os 
primeiros guias, inventários, catálogos específicos surgiram nos anos 90. Ressalto o pioneirismo dos projetos Guia de Fontes para a História Indígena e do Indigenismo em Arquivos Brasileiros (1994), coordenado por John Monteiro e Os Índios em Arquivos do Rio de Janeiro (1995), organizado por José Ribamar Bessa Freire, com informações arquivísticas tão somente do Rio de Janeiro, ferramentas imprescindíveis para 'caminhar' entre coleções, fundos, códices dos arquivos.

O Guia de Fontes para a História Indigena e do Indigenismo em Arquivos Brasileiros mapeou uma vasta documentação histórica em arquivos das capitais brasileiras, apresentando um minucioso panorama dos acervos, reunindo desde informações básicas como endereços, telefones das instituições - a dados específicos a respeito de coleções, fundos, estado de conservação documental, ações de preservação, divisões políticoadministrativas, ordens religiosas, dados etnográficos, linguísticos e demográficos de variados povos indígenas mencionados nos documentos (com índices de etnias, temático, geográfico e onomástico) contemplados nos cojuntos documentais. Luís Grupioni (1995) lembra que o projeto revelou "que os arquivos brasileiros guardam documentos muito mais abundantes do que se esperava e traz à tona personagens, acontecimentos e processos sobre os quais pouco ou nada se sabia".

As pesquisas realizadas no Rio de Janeiro, sob a coordenação de Bessa Freire, resultaram na publicação Os Índios em Arquivos do Rio de Janeiro, em dois volumes. O guia reúne os esforços investigativos (dois anos de trabalho) nos arquivos da capital fluminense, assim como em acervos cartoriais, municipais, judiciários do estado. O objetivo era procurar "manuscritos que constituíssem pistas para reconstruir os fios históricos da sociedade brasileira naquilo que ela tem de mais frágil: os grupos indígenas", explica Bessa Freire (1995, p. 8). Nesse sentido, esses instrumentos de pesquisa podem ser compreendidos como fronteiras, marcos delimitadores de acervos específicos sobre os povos indígenas, tendo em vista que os conjuntos documentais das instituições arquivísticas abrangem distintas temáticas espaços-temporais. Dentro dos arquivos, portanto, há outros acervos e nesse sentido, os instrumentos de pesquisas concernentes aos índios criam arquivos peculiares que não necessariamente estão reunidos, de modo geral, sob um mesmo fundo, coleção, códice, série, gaveta, sala ${ }^{3}$.

Igualmente relevantes são os catálogos e inventário: Documento para a História Indígena no Nordeste (1994), organizado por Maria Sylvia Porto Alegre, Marlene da Silva Mariz e Beatriz Góis Dantas, no qual as pesquisadoras enfatizaram a documentação sobre as temáticas indígenas existente nos arquivos nordestinos do Ceará, Rio Grande do Norte e

\footnotetext{
${ }^{3}$ Cabe ressaltar que no Arquivo Público do Estado do Rio de Janeiro (APERJ) os documentos sobre os povos indígenas no século XIX estão reunidos no Fundo Presidente da Província do Rio de Janeiro (PP), conforme o guia "Os Índios em Arquivos do Rio de Janeiro".
} 
Sergipe; Documenta Indígena do Brasil Central, de Jézus Marco de Ataídes (2001), reúne informações referentes aos índios no estado de Goiás e Povos Indígenas no Sul da Bahia Posto Indígena Caramuru - Paraguaçu (1910 e 1967), editado pelo Museu do Índio/RJ (2002) destinado aos Pataxó Hãhãhãe, todavia abarca documentos relacionados aos Maxacali, KiririSapuya, Kamacan. Elaborado a partir da documentação do Fundo SPI (Serviço de Proteção ao Índio) a respeito dos índios no sul baiano, a publicação disponibilizou documentos que forneceu subsídios em ações na justiça para a identificação de terras indígenas. No livro, encontram-se registros sobre as relações do Estado com essas populações, histórias de conflitos e litígios, violências e abusos cometidos contra essas populações na região, registros de estratégias indígenas para garantir seus direitos e manter seus territórios invadidos, entre outros temas.

Com relação à produção mais atual desses instrumentos de trabalho, vale destacar o Projeto Resgate "Barão do Rio Branco", do Ministério da Cultura, criado institucionalmente em 1995, no âmbito da Comissão Bilateral Luso-Brasileira de Salvaguarda e Divulgação do Patrimônio Documental (COLUSO), com o objetivo de inventariar toda a documentação manuscrita sobre o Brasil colonial, existentes em instituições internacionais, especialmente Portugal, pois o Arquivo Histórico Ultramarino de Lisboa (AHU) é o maior acervo de documentação colonial brasileira no exterior. Coordenado por Esther Bertoletti (até 2011), o projeto arquivístico reuniu mais de 100 pesquisadores, centenas de instituições públicas e privadas e abrangeu acervos em nove países (RICARTE, 2011).

A iniciativa de preservação em meio digital das fontes do AHU microfilmou 2400 caixas, contendo aproximadamente 300.000 documentos, organizados em três fundos: o Conselho Ultramarino (Séc. XVI a 1833); a Secretaria de Estado da Marinha e Ultramar (18341910) e o Ministério do Ultramar (1910-1975), segundo Bertoletti, Bellotto e Dias (2011). O conjunto documental foi digitalizado e transferido para o Brasil em 316 CD-ROMs, permanecendo uma cópia de segurança na Biblioteca Nacional e outras cópias foram entregue aos arquivos estaduais com a documentação relativa a seus respectivos territórios. O que há em mais de duas mil caixas? Um acervo de valor inestimável por sua diversidade documental e abrangência espaço-temporal: alvarás, cartas de lei, cartas régias, provisões, decretos, instruções, portarias, cartas de mercês (concedendo sesmarias, postos militares ou civis), requerimentos, ofícios, cartas, representações, pareceres, abaixo-assinados, avisos, escritos de secretário, ofícios, bilhetes, coleções iconográficas e cartográficas (Bertoletti, Bellotto e Dias, 2011), produzidos por variados atores (até mesmo por índios) no período colonial e pós-independência.

Como parte dos resultados, foram publicados diversos inventários e catálogos no Brasil e no exterior, que divulgaram importantes documentos para a história indígena e o indigenismo brasileiro. Entre as publicações, recentemente foi editado o Catálogo Geral dos 
Manuscritos Avulsos e em Códices referentes à História Indígena e Escravidão Negra do Brasil (2016), organizado por Juciene Ricarte. De âmbito nacional, a pesquisa mapeou, catalogou e organizou duas coleções de documentos voltados para a história indígena e a escravidão negra (produzidos entre 1581 e 1843), incluindo a elaboração de verbetes disponibilizados em áudios, destinado aos deficientes visuais. Ricarte (2011), ao analisar os impactos dos primeiros inventários, guias, catálogos de fontes sobre os índios nos estudos históricoantropológicos desenvolvidos na área de história, constatou maior visibilidade aos acervos, outrora desconhecidos e esquecidos, além do aumento de pesquisas, visíveis na significativa produção de monografias, dissertações, teses defendidas em cursos e programas de pósgraduação de história no Brasil. Assim, a construção de instrumentos de investigação em arquivos nos parecem estimular novos estudos sobre os povos indígenas, representando uma contribuição para o conhecimento dessas sociedades e (por que não?) da nossa própria história e memória social.

\section{ANTROPÓLOGOS E ARQUIVOS}

Se por um lado, temos na historiografia um movimento de aproximação, valorização e visibilidade dos povos indígenas (incluindo a construção de instrumentos de pesquisas específicos que estimulam e tornam possível a realização de estudos sobre os índios no Brasil), de igual modo, há na antropologia uma movimentação, porém em direção aos arquivos. Para Olívia Cunha (2004), a relação de proximidade é em função de vários processos de institucionalização da disciplina, principalmente a partir dos anos 80, quando um conjunto de fatores direcionou a atenção de antropólogos para a produção de conhecimentos de seus pares, especificamente para os acervos que Olívia Cunha chama de "arquivos etnográficos e seu duplo, os arquivos pessoais", definidos como "construções culturais cuja compreensão é fundamental para entendermos como certas narrativas profissionais foram produzidas e como sua invenção resulta de um intenso diálogo envolvendo imaginação e autoridade intelectual" (2004, p. 296; grifos da autora). Outro fator diz respeito à relativização da noção de campo na antropologia, surgindo novas abordagens teórico-metodológicas, além de outras áreas como a antropologia urbana.

Para Castro e Cunha (2005), o interesse dos antropólogos nos arquivos é recente, cada vez mais intenso e tem proporcionado o surgimento de pesquisas nos arquivos e sobre os arquivos, campo tradicionalmente associado a historiadores e arquivistas. Nesse sentido,

\footnotetext{
"Além de utilizar arquivos como fonte de conhecimento para a produção de suas análises, desde, pelo menos, os anos 1980, os antropólogos têm refletido sobre a natureza de registros documentais transformados em fontes e, em alguns casos, têm produzido e/ou organizado arquivos e coleções a partir de uma perspectiva antropológica" (CASTRO; CUNHA, 2005, p. 04).
} 
Essa perspectiva antropológica tem sido chamada - por Olívia Cunha, Celso Castro e outros pesquisadores - de antropologia no/do arquivo, que tem como principal característica a compreensão do arquivo como campo "povoado por sujeitos, práticas e relações suscetíveis à análise e à experimentação antropológica" (CASTRO e CUNHA, 2005, p. 4). O que implica refletir, não somente, a respeito do uso de documentos arquivísticos nas pesquisas antropológicas e a sua relação com a produção etnográfica, mas também a construção e disposição de arquivos e coleções de antropólogos (textuais, imagéticas, sonoras), de instituições de antropologia ou aquelas de interesse para a área, como explicam Celso Castro e Olívia Cunha acima.

A questão que nos interessa nos debates fomentados pela antropologia no/do arquivo é a concepção dos arquivos como campo. Dessa forma, em recente pesquisa, estabeleci uma relação entre arquivos e territórios indigenas e, desse modo analisei os arquivos como campo, ou melhor, territórios indigenas bastante singulares para os estudos das populações indígenas no passado quanto no presente, especialmente os índios na cidade do Rio de Janeiro oitocentista (SILVA, 2016). Assim, arquivo como território indígena é um importante recurso metodológico no "trabalho de campo" em acervos de instituições ou pessoais, pois se para os antropólogos os arquivos são campos, para os historiadores eles podem ser territórios indígenas enriquecedores, fundamentais para analisar, entre outros aspectos, o movimento dos índios na História como protagonistas que foram e são.

Tendo os acervos arquivísticos de instituições do Rio de Janeiro como territórios indígenas, cujas fronteiras começaram a ser delimitadas por instrumentos de pesquisas específicos (particularmente o guia de fontes Os Índios nos Arquivos do Rio de Janeiro), interessa refletir acerca do contexto histórico, sociocultural da população indígena no espaço urbano, precisamente na corte - fluxo migratório e as motivações dos deslocamentos; memórias, histórias de vida, tipos de relações e negociações ali por eles estabelecidas - e, menos no que os arquivos dizem (ou silenciam) sobre os povos indígenas. Essa sutil inversão me permite realizar essa reflexão a partir dos pressupostos teóricometodológicos da antropologia no arquivo, em detrimento de uma antropologia do arquivo. Vale lembrar que os chamados 'territórios indígenas' ainda não foram totalmente demarcados, pois parte significativa da documentação histórica (textual, imagética, sonora) sobre os índios continua desconhecida, pouco sistematizada, aflorando de modo tímido nos instrumentos de pesquisas: catálogo, fichários, guia de fontes, índices dessas instituições.

\section{NOS TERRITÓRIOS INDÍGENAS: ÍNDIOS NA CIDADE DO RIO}

Discorrer sobre a presença dos índios na cidade do Rio de Janeiro no século XIX, com base na importância que esse segmento da nossa sociedade teve (e continua) na 
construção espacial, sociocultural, linguística da capital fluminense, impõe ao pesquisador o desafio de 'caminhar no passado' através da documentação histórica, pois não há nenhuma sociedade indígena, especificamente do período, ali vivendo, permitindo assim uma conexão mais particular entre o antes e o atual. Desse passado, embora existam memórias, patrimônios culturais e linguísticos, iconografias, monumentos, todos testemunhas das trajetórias desses atores e suas relações ali estabelecidas, é mediante a leitura e análise da documentação histórica que os índios ganham silhueta mais consistente, vozes e rostos, adquirem vida. Nesse sentido, "O arquivo é uma brecha no tecido dos dias, a visão retraída de um fato inesperado. Nele, tudo se localiza em alguns instantes de vida de personagens comuns, raramente visitados pela história (...)" adverte Farge (2009, p.14).

É o caso de centenas de indígenas (crianças, mulheres e homens) desconhecidos e silenciados em fundos, coleções, códices, pois nos principais arquivos do Rio de Janeiro (parte de abrangência nacional) existe uma vasta e preciosa documentação sobre os povos indígenas no Brasil, abrangendo tempos e espaços diferenciados, que seguem fragmentados, dispersos em dezenas de instituições arquivísticas existentes na capital fluminense como o Arquivo Nacional (ANRJ), o Arquivo Público do Estado do Rio (APERJ), o Arquivo Geral da Cidade do Rio (AGCRJ), a Biblioteca Nacional (BNRJ), a Biblioteca do Instituto Histórico e Geográfico Brasileiro (IHGB), a Biblioteca do Museu do Índio, o Serviço de Documentação da Marinha (pertencente ao Departamento de Patrimônio Histórico da Marinha - DPHDM), o Museu da Justiça (MJRJ), entre outros.

Mapear e identificar a documentação para encontrar os índios, em quilômetros de papéis e imagens (tendo em vista o foco da pesquisa), ainda não é uma tarefa fácil. Assim como nos territórios indígenas (para ficarmos circunscritos ao objeto de nossa discussão) o desenvolvimento da pesquisa de campo exige, entre outros, metodologia, teoria, especialmente o modo de inserção do pesquisador na localidade e comunidade desejada, nos arquivos-territórios indígenas também é necessário: prudência, cautela, paciência, sorte. Além disso, chamo a atenção para o caráter seletivo dessas instituições, pois estamos falando de órgãos criados pelo Estado, interessados em oficializar um tipo de memória, em detrimento de tantas outras. O arquivo é uma "instituição que canoniza, cristaliza e classifica o conhecimento de que o Estado necessita, tornando-o acessível às gerações futuras sob a forma cultural de um repositório do passado neutro" (DIRKS apud CUNHA, 2004, p. 292). Nesse sentido, a fala de Bessa Freire (1995, p. 8) segue bastante atual:

\footnotetext{
"Uma das maiores dificuldades encontradas pelo pesquisador reside justamente na localização e identificação das fontes primárias disponíveis. As fontes escritas produzidas pela prática administrativa, comerciante, missionária e exploradora da geografia do continente nos últimos 500 anos, conservadas nos arquivos, não foram suficientemente interrogadas e nem sequer ordenadas e catalogadas". (BESSA FREIRE, 1995)
} 
Em contrapartida, projetos de identificação, mapeamento e digitalização de manuscritos sobre os povos indígenas, como visto, estão mudando essa realidade, catalogando e disponibilizando informações acerca dessas sociedades, produzidas no período colonial e pós-colonial. Gradativamente, esses "territórios indígenas" ganham fronteiras mais nítidas, deixando entrever de forma mais clara e acessível eles, os índios.

A presença indígena na cidade do Rio está documentada no século XIX em registros diversos - jornais, relatos de viajantes, pintores, naturalistas; mas também em manuscritos de diversas naturezas: correspondências entre distintas autoridades, recenseamentos populacionais, registros cartoriais, relatórios ministeriais, de presidentes de províncias e de intendentes da polícia, dados de vacinação, processos criminais, entre outros. No censo demográfico de 1872 (primeiro realizado no Brasil), por exemplo, foram recenseados 923 indígenas na capital do Império, a maior parte proveniente do Rio de Janeiro, mas existiam migrantes de províncias como Ceará, Pará, Minas Gerais, Espírito Santo. Cotejando dados censitários com relatos de viajantes, naturalistas, periódicos de época, atas da Câmara Municipal foi possível identificar o modo como eles viviam na capital do Império, a maioria, em situações precárias, por ruas, casas de particulares, localidades populares, cortiços (SILVA, 2016). Outros marginalizados, sem emprego e domicílio vagavam por tabernas e vendas de bairros como Candelária, Santa Rita e São José, em permanentes conflitos com a polícia (BESSA FREIRE e MALHEIROS, 2009, p. 83). Nesses espaços, rapidamente eram transformados em caboclos (considerados, portanto já 'civilizados'), pois longe de suas comunidades tradicionais, com nomes cristãos e usando vestimentas dos "brancos" (alguns falando o português) eram vistos por autoridades e habitantes não mais como índios.

Diferente dos atuais bairros indígenas nas cidades, não foi possível identificar no Rio de Janeiro nenhuma comunidade nos documentos pesquisados, embora eles mantivessem, em determinadas circunstâncias, alguns contatos. Os índios estavam dispersos, todavia, vivenciando situações diversas. Os lugares mais privilegiados dessa cidade-paisagem, que já se desenhava assim na época, não pertenciam aos índios, mas à elite, nobres, ricos fazendeiros, intelectuais. Estes (ao contrário de indígenas, negros, ciganos, vadios, pobres) viviam em regiões mais afastadas da capital imperial, fugindo dos cortiços e das epidemias que assolavam a localidade nos anos 50 e 60, cujo foco de doenças para muitos estava nessas estalagens (CHALHOUB, 2006).

Motivados por diferentes razões, durante todo o século XIX, índios migravam, forçadamente ou não, de diferentes regiões para o Rio de Janeiro - principal centro de poder político e econômico da época - onde viviam em casas de particulares trabalhando como doméstico - foi o caso de Maria Caetana, índia violentada por um grupo de "facinorosos" no ambiente em que trabalhava e residia (1818), fato que nos permite refletir sobre o tipo de tratamento ali concedido às mulheres indígenas -, realizavam serviços na 
pesca de baleias, vendiam água potável e seus artigos de arte nas ruas (inclusive plantas medicinais e as chamadas mezinhas), exerciam a função de correios (transportando mercadorias e escravos). Eles também sobreviviam da lavagem de vestimentas, conforme a emblemática imagem (desenho $n^{022}$ ) de Jean-Baptiste Debret (1834), registro raro de uma família de caboclos, residentes há vários anos no Rio, que lavavam roupas no inexistente rio do Catete.

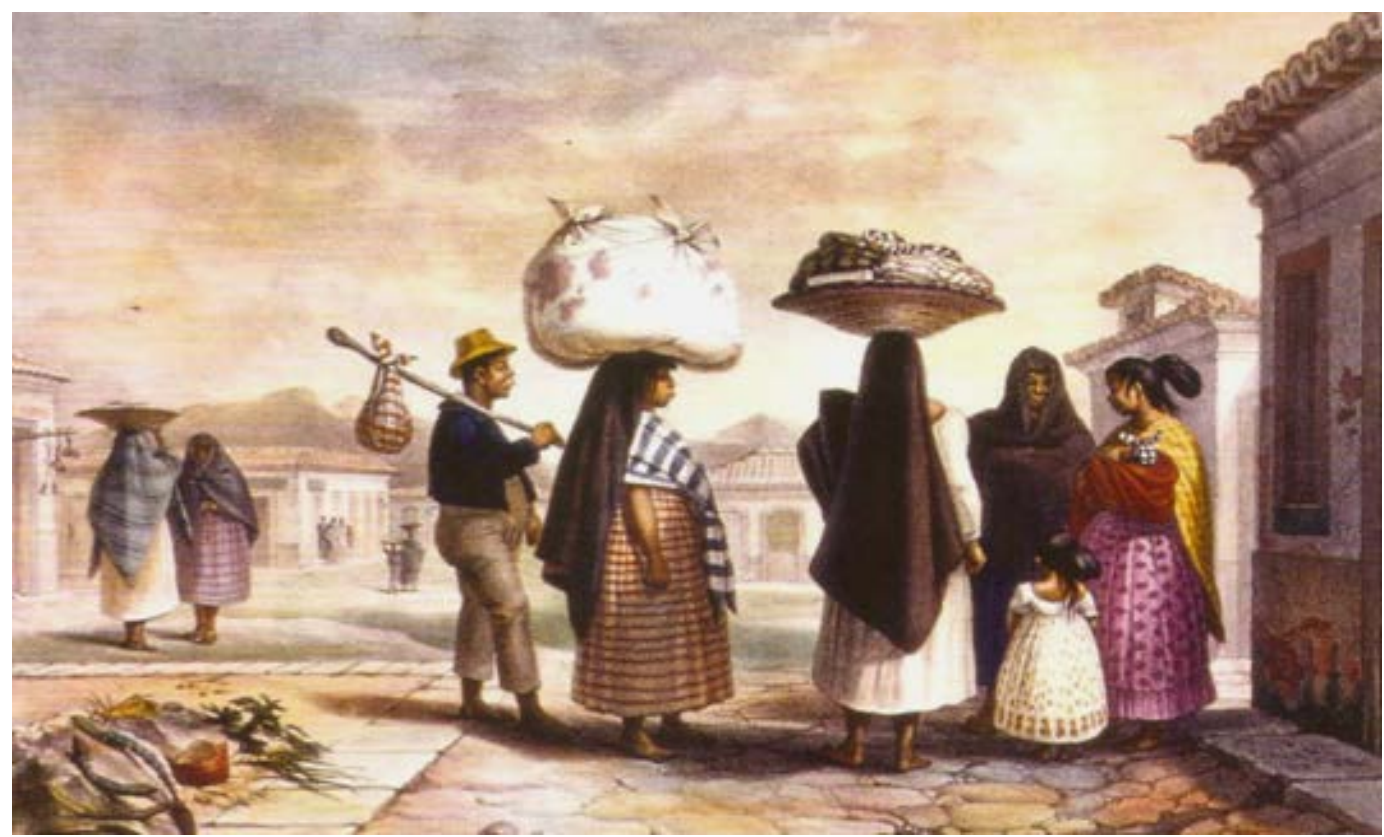

Figura 1: Lavadeiras índias em pleno Catete. Fonte: Jean-Baptiste Debret (1834).

Deste modo, partes significativas de suas trajetórias de vidas, cotidianos, memórias foram registradas em textos e imagens importantes para se discutir as múltiplas situações e redes de interações por eles estabelecidas naquele espaço urbano.

Recrutados à força, prestavam serviços militares obrigatórios ao "El Rey" nas obras públicas, Arsenal da Marinha, Armada, Exército, Guarda Nacional - exercendo diferentes funções, como o índio Guarani (soldado de artilharia) eternizado por Debret.

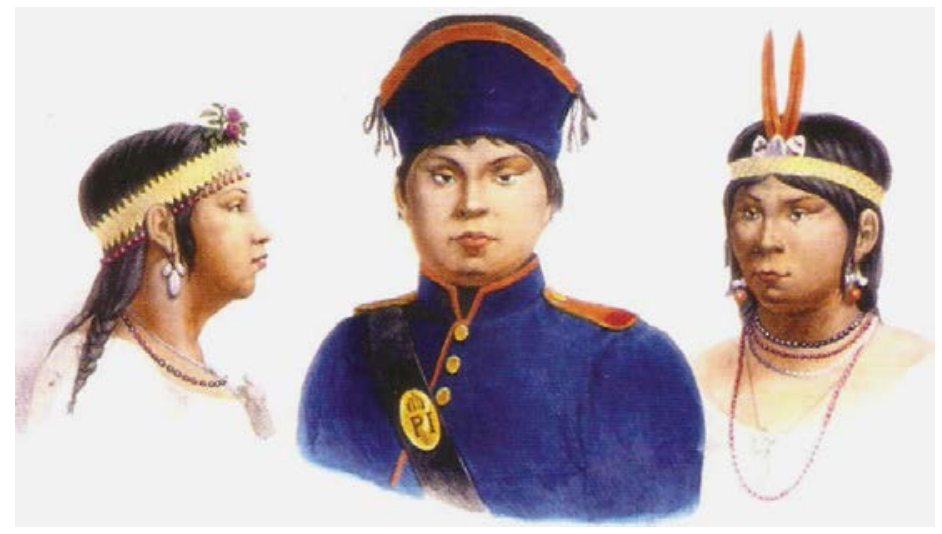

Figura 2: Índio Guarani servindo como soldado de artilharia no Rio de Janeiro. Fonte: Debret (1834). 
Lembro que nas Forças Armadas diversos índios eram remetidos à corte ainda crianças, com faixa etária entre 7 a 12 anos, para aprenderem um ofício nas escolas, conforme os livros de Socorros da Marinha - registros de recrutas, em geral, fichas que documentam algumas informações sobre os soldados: ano do alistamento, nome, classe, naturalidade, idade, estado civil, estatura, cor, tipologia do cabelo, cor dos olhos, filiação, existência ou não de barba e, por último, o registro informava as razões do recrutamento. No Arquivo da Marinha e nos porões do Arquivo Nacional, encontrei alguns livros de Socorros de meninos índios, remetidos de outras províncias, mas também do Rio de Janeiro e de prisões (detidos por vadiagem, brigas, entre outras razões).

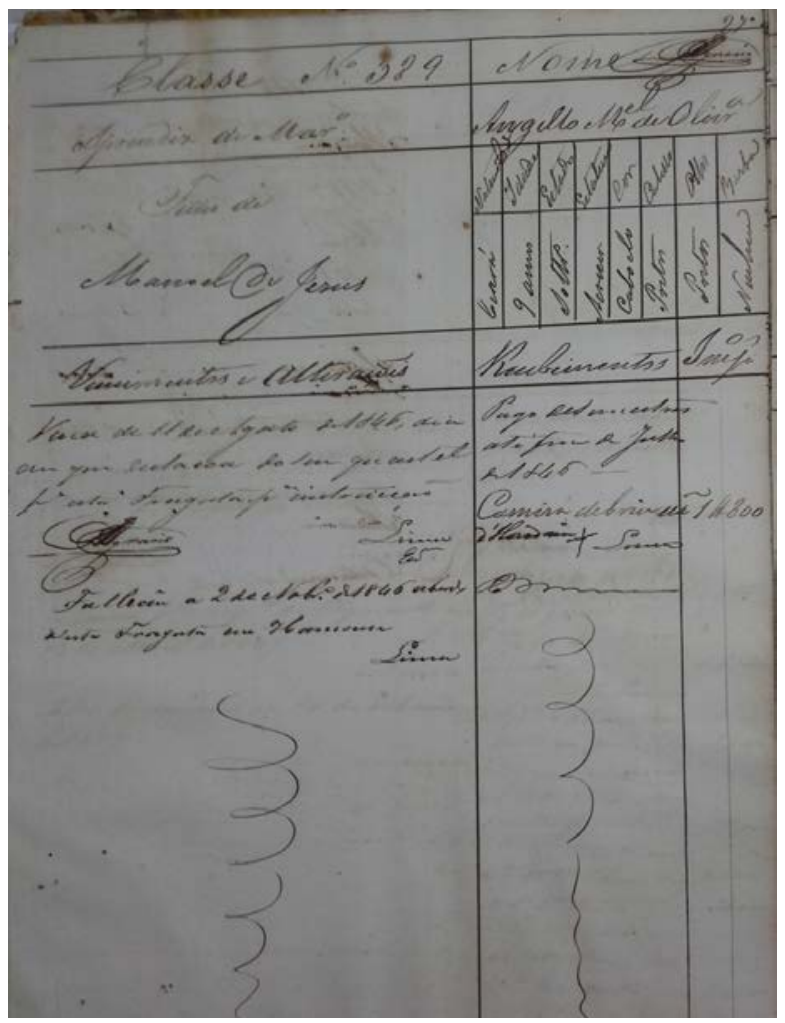

Figura 3: Ficha de Angello Manoel de Oliveira. Fonte: Livro de Socorros da Marinha (ANRJ).
Entre as histórias de vidas ali documentadas, enfatizo o caso do pequeno índio Angello Manoel de Oliveira, de 9 anos, filho de Manoel de Jesus, originário da província do Ceará, remetido ao Arsenal da Marinha para ser aprendiz de marinheiro. Рага receber as instruções necessárias, ele fora enviado a uma fragata, em 11 de agosto de 1846, todavia faleceu pouco meses depois, em 2 de novembro, na embarcação, conforme a sua ficha de assentamento (Livros de Socorros da Marinha, ANRJ).

No Arsenal da Marinha, os índios trabalhavam em diferentes repartições, como aponta o ofício do inspetor da Marinha, datado de 04 de janeiro de 1809.

"Os Índios dos diferentes Armazens e Repartições continuaram nos seus destinos, igualmente os da Aguada e da Barca d'Agua e com a gente das embarcações miúdas, quando não estão empregados auxiliados com algum destacamento dos navios armados".

Além das repartições da Aguada (lugar onde se abasteciam de água a frota naval), Barca d'Água e embarcações miúdas, trabalhavam na fabricação de suprimentos navais, prestavam serviços de marinhagem, de cabotagem. Acreditava-se, todavia, que eles tinham certa aptidão para o trabalho de remeiros. O número de índios no Arsenal da Marinha, em 1809, ега bastante expressivo, como mostra a Relação dos pagamentos feitos por José de Souza Netto, pagador dos Armazéns Reais, aos moços índios serventes do Arsenal e remeiros dos diferentes escaleres da Ribeira, Contadoria da Marinha 9 de 
fevereiro de 1809 (Biblioteca Nacional/RJ). O documento é uma listagem com centenas de índios (149 pessoas, no total) que prestavam serviços nos Armazéns reais e trabalhavam como remeiros nas embarcações Galeota, Savana, Escaleres (?) e da Ribeira, apresentando importante panorama da presença indígena no Arsenal da Marinha naquele ano. Cuidadosamente os índios foram nomeados, seus saldos (de seus respectivos pagamentos) registrados - incluindo as despesas com gastos diversos e hospitais (sinalizado pela inclusão do H). Segue abaixo um trecho do manuscrito.

\section{Pagamentos aos indígenas no Arsenal da Marinha e Armazéns Reaes}

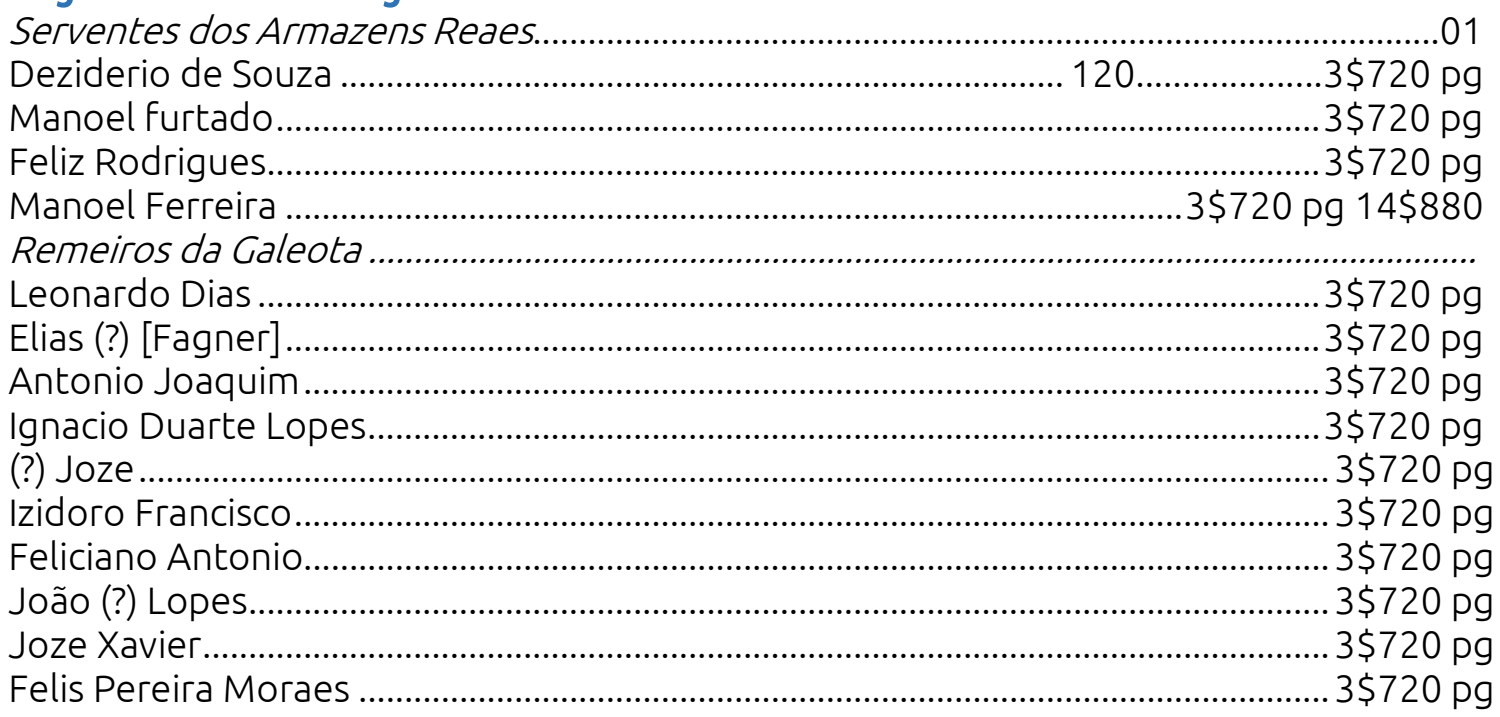

Na listagem acima, entre os remeiros dos Escaleres (?) e da Ribeira encontramos o registro do índio Bernardino Soares, cuja história é bastante singular, considerando as condições de vida e trabalho dos índios nas instalações da Marinha. Cotejando a lista da contadoria com os relatórios dos inspetores do Arsenal sabemos que Bernardino Soares era "Índio antigo" nos serviços daquele Arsenal, atuando como "remador e patrão interino das embarcações miúdas" (ganhando $4 \$ 960$ réis), conforme o ofício de José de Santa Rita, datado de 19 de outubro de 1814 (Arquivo da Marinha, RIM, p. 238). No documento, o inspetor encaminhava ao ministro da Marinha, Inácio da Costa Quintela, o requerimento do índio, no qual Bernardino Soares "já pela impossibilidade de moléstias, já pela idade" informava que não poderia continuar exercendo o cargo e a função. Para atender "a este homem já antigo e sempre afetivo", Santa Rita julgava ser necessário "para o restante de sua subsistência metade do salário que percebe neste Arsenal, ou o que fôr do Real Agrado de Sua Alteza Real, quando haja de the conferir esta graça" (Arquivo da Marinha, RIM, p. 238). É possível que o índio Bernardino Soares tenha sido agraciado com uma pensão (prática recorrente na época, solicitada também por índios), todavia não foi possível localizar (na documentação pesquisada) a resposta ao requerimento por ele enviado. A história desse 
índio, contudo, é importante para analisarmos as atuações e negociações tecidas por esses atores no espaço urbano, enfatizando o protagonismo indígena na História. Diferente de Bernardino, a maioria dos índios que prestavam serviços militares vivia em péssimas condições de vida e trabalho, ganhando baixos soldos.

Os trabalhos forçados e a baixa remuneração estão entre as principais razões de revoltas e deserções contínuas. São comuns os ofícios dos inspetores da Marinha com diversas queixas e pedidos solicitando novas levas de índios. O inspetor Verissimo Máximo de Almeida, em 2 de dezembro de 1815, expediu um ofício reclamando do não comparecimento de um índio, Manoel, remetido da aldeia Velha (Rio de Janeiro), conforme o trecho a seguir.

"Remeto a V. Exa. por copia a relação de Índios que me foram remetidos da Aldeia Velha, os quais tendo-se-me apresentado ontem, de Assunção, já hoje deixou de comparecer, Manoel compreendido naquela relação".

O mecanismo de recrutamento da força de trabalho indígena era possível, na maioria dos casos, graças às alianças de agentes do governo com líderes das aldeias, os chamados capitães mores, (tuxauas ou principais, mais recorrentes na região Norte). Essas alianças estão evidenciadas em distintos documentos, como os requerimentos e cartas do índio José Pires Tavares, capitão mor do aldeamento de São Francisco Xavier de Itaguaí (localizado no atual município de Itaguaí, Rio de Janeiro). O chefe indígena enviou uma carta, em 25 de maio de 1805, ao vice-rei relatando as dificuldades de enviar novos recrutas para "exercer o serviço de sua alteza real, da pesca de baleias" e, igualmente para o serviço nas forças armadas (SOUZA SILVA, 1854, p. 373).

Tavares alegava que os índios casados retornam à aldeia sem nada "Nú (nus), sem trazerem com que cobrir as necessidades de suas mulheres e filhos" e que os solteiros, enviados para o serviço na pesca de baleia "dita pesca" não retornavam à aldeia. Indiretamente, nas entrelinhas da carta, o chefe indígena criticava a política de recrutamento da Coroa portuguesa. Cabe destacar que na província fluminense, os índios que 'assentavam praça' (alistavam-se) no Arsenal, nas primeiras décadas do século XIX, eram recrutados principalmente dos aldeamentos de Mangaratiba, São Gonçalo, Itaguaí, São Lourenço, Cabo Frio e Vila Nova, segundo os registros do inspetor da Marinha, documentado em 27 de dezembro de 1817 (Arquivo da Marinha, RIM).

Descontentes com seus pagamentos, os índios desertavam e uma das alternativas para viver nas cidades era trabalhar na pesca de baleias. Fato que desagradava e muito os inspetores do Arsenal Marinha da Corte (como era mais conhecido na época). A mão de obra indígena era disputa por inspetores e administradores da pesca de baleias (não apenas, pois a Câmara municipal também disputava e frequentemente os recrutavam para as obras 
públicas). No ofício de 03 de junho de 1809, o administrador Geral Real Administração de Pesca das Baleias reclamava o Índio Manoel da Conceição, preso por deserção.

"(...) Tenho a honra de pôr na presença de Vossa Alteza o oficio que me foi dirigido pelo Administrador Geral da Real Administração de Pesca das Baleias, reclamando o Índio Manoel da Conceição, pelas razões que constam do mesmo ofício, o qual o Índio me foi com efeito remetido, prêso, pelo Coronel do competente distrito, por ser desertor dêste Arsenal" (Ofícios do Inspetor da Marinha 1808-1814, p. 76-77).

Debret $(1834,21)$ registrou a "aptidão" para a navegação dos caboclos de São Lourenço (ideia compartilhada por governantes, políticos sobre os povos indígenas), pois no Arsenal da Marinha, relata o francês, trabalhavam vários caboclos, alojados com suas famílias, especialmente empregados nos "serviços de canoas particulares do imperador do Brasil". Os descendentes de Araribóia tinham fama de bons marinheiros, como observou Carl Schlichthorst ([1829] 2000, p. 153) e "No remar e dirigir canoas não são menos hábeis" documentou Luccock ([1820] 1975, p. 174). Thomas Ewbank ([1856] 1976, p. 210) documentou o momento exato do desembarque de "centenas de recrutas" vindos da região Norte do Império - um terço eram índios. Indagados sobre o tempo de alistamento, eles responderam que não se alistavam "São agarrados e obrigados a servir". Os presidentes das províncias tinham ordens para enviar os indivíduos considerados desordeiros, e os índios que pudessem apanhar (SILVA, 2016). Foi o que aconteceu, em 1826, com o principal líder dos índios de Pacatu (um dos aldeamentos da província de Sergipe), condenado aos serviços da Marinha por divergir e lutar contra os proprietários de um engenho próximo às terras indígenas (DANTAS, SAMPAIO, CARVALHO, 1992, p. 448).

Agarrados e obrigados a servir, centenas, talvez milhares, de índios desembarcaram na cidade do Rio de Janeiro no século XIX. Ali, teceram novas redes de interações e relações no espaço urbano, escrevendo outra história.

\section{CONSIDERAÇÕES FINAIS}

A presença de indígenas na cidade do Rio de Janeiro no século XIX permite uma reflexão mais abrangente do fenômeno dos índios em contextos urbanos. Esta cidade que outrora fora habitada por distintos povos aguerridos e imponentes, palco de embates violentos, no século XIX abrigava centenas de índios em cortiços, subúrbios, ruas, cadeias e dependia de sua mão de obra para ali viverem. Por outro lado, recebia algumas lideranças indígenas de diferentes localidades do estado ou de outras regiões do Brasil com o objetivo, entre outros, de reivindicarem seus direitos, fundamentalmente suas terras invadidas.

Se na primeira metade do século XIX encontramos diferentes documentos que retratam parte do cotidiano dos grupos indígenas no estado do Rio e no Município Neutro, na segunda são cada vez mais raras as informações. Aos poucos os índios deixam de figurar 
na documentação oficial, sendo relegados ao silêncio e esquecimento. Uma tentativa política de apagá-los da história, da memória social fluminense.

\section{REFERÊNCIAS}

ARQUIVO Nacional - Série Marinha Livros de Socorros - Aprendizes marinheiros da Fragata Constituição, 1846-XVII M 134.

ARQUIVO da Marinha - Diretoria do Patrimônio Histórico e Documentação da Marinha (DPHDM) Relatórios do Inspetor da Marinha (1809 a 1815)

Biblioteca nacional - Anais, vol. 104, documento 129 - 20, 04, 002 n83 - Relação dos pagamentos feitos por José de Souza Netto, pagador dos Armazéns Reais, aos moços índios serventes do Arsenal e remeiros dos diferentes escaleres da Ribeira, Contadoria da Marinha 9 de fevereiro de 1809.

BERTOLETTI, Esther Caldas, BELLOTTO, Heloísa Liberalli, DIAS, Erika Simone de Almeida Carlos. 0 projeto resgate de documentação histórica Barão do Rio Branco: acesso às fontes da história do Brasil existentes no exterior. Clio - Revista de Pesquisa História, n. 29.1, p.1-26, 2011.

BESSA FREIRE, José Ribamar. Os Índios em Arquivos do Rio de Janeiro. Rio de Janeiro: Nepe/UERJ, 1995 , vol. I ell.

BESSA FREIRE, José Ribamar e MALHEIROS, Márcia. Aldeamentos Indígenas do Rio de Janeiro. $2^{\text {a }}$ ed. Rio de Janeiro: EdUERJ, 2009.

CARNeIRO DA CUNHA, Manuela. História dos Índios no Brasil. (coord.) São Paulo: Companhia das Letras, 1992.

CASTRO, Celso e CUNHA, Olívia Maria G. Quando os arquivos são campos. Estudos Históricos, v.2, n.36, 2005.

CHALHOUB, Sidney. Cidade febril - cortiços e epidemias na Corte imperial. São Paulo: Companhia das Letras, 2006.

CUNHA, 0. M. G. da. Tempo Imperfeito: Uma etnografia do arquivo. Mana 10(2): 2004, p. 287-322.

DANTAS, Beatriz G., SAMPAIO, José Augusto L. e CARVALHO, Maria Rosário G. de. Os Povos Indígenas no Nordeste Brasileiro. In: CARNEIRO DA CUNHA, Manuela (coord.), História dos Índios no Brasil. São Paulo: Companhia das Letras, 1992, p.431-456.

DEBRET, Jean Baptiste. Voyage pittoresque et historique au Brésil. Paris: Institut de France, 1834, vol.1.

DIRKS, Nicholas. The imperial archive: colonial knowledge and colonial rules. In: DIRKS, Nicholas (org.), Castes of mind: colonialism and the making of modern India. Princeton: Princeton University Press, p. 107-124, 2001.

EWBANK, Thomas. A vida no Brasil. São Paulo e Belo Horizonte, Edusp/ltatiaia, 1976. [1856] 
FARGE, Arlette. 0 sabor do arquivo. São Paulo: Edusp, 2009.

LUCCOCK, John. Notas sobre o Rio de Janeiro e partes meridionais do Brasil. São Paulo e Belo Horizonte, Edusp/Itatiaia, 1975. [1820]

GINZBURG, C. Sinais, raízes de um paradigma indiciário. In: GINZBURG, C. Ginzburg (ed.), Mitos, emblemas, sinais: morfologia e história. São Paulo: Companhia das Letras, 1991 p.143-80.

GRUPIONI, Luis Benzi. Guias de fontes para a História Indígena. RBCS, v. 10, n.29, São Paulo, Out. 1995. (Resenhas)

MONTEIRO, J. Tupis, Tapuias e historiadores: estudos de história indígena e do indigenismo. Tese de Livre Docência, UNICAMP, Campinas, 2001.

Entre o Etnocídio e a Etnogênese: Identidades Indígenas e Coloniais. In: Tempos índios: Histórias e narrativas do Novo Mundo. In: FAUSTO, C. e MONTEIRO, J. (Orgs.) Lisboa: Assírio \& Alvim, 2007.

SANTILI, Márcio. Os brasileiros e os índios. São Paulo: 2000.

RICARTE, Juciene. Documentos e Instrumentos de pesquisa de História Indígena e do Indigenismo d'Aquém e d'Além-Mar Atlântico: uma discussão "necessária, urgente e inadiável". In: XXVI ANPUH Simpósio Nacional de História - ANPUH -, 2011, São Paulo. Anais do XXVI ANPUH - Simpósio Nacional de História. São Paulo: USP, v.1, p.1-15, 2011.

SCHLICHTHORST, Carl. 0 Rio de Janeiro como é (1824-1826): uma vez e nunca mais: contribuições de um diário para a história atual, os costumes e especialmente a situação da tropa estrangeira na capital do Brasil. Brasília: Senado Federal, 2000. (0 Brasil visto por estrangeiros) [1829]

SILVA, Ana Paula da. 0 Rio de Janeiro continua índio: território do protagonismo e da diplomacia indígena no século XIX. Rio de Janeiro, UNIRIO - Centro de Ciências Humanas, 2016. Tese de doutorado em Memória Social.

SOUZA SILVA, Joaquim Norberto de. Memória histórica e documentada das aldeias de índios da província do Rio de Janeiro. Revista do Instituto histórico e geográfico do Brasil, t. XVII, $3^{\text {a }}$ série, n.14, 1854.

Recebido em 30 de julho de 2017. Aprovado em 25 de janeiro de 2018. 